\title{
Boundary work of dentists in everyday work
}

Cecilia Franzén, Faculty of Odontology, Malmö University, Malmö, Sweden

Abstract - Objective: The Swedish policy objectives in dental care provision - to meet public demands for dental care and to increase the cost-effectiveness of the service require dentists to work in teams with dental hygienists and dental nurses. This study focused on the role of dentists in the distribution of work tasks within teams in one Swedish Public Dental Service organisation. Dental clinics were viewed as micropolitical arenas in which dentists attempt to demarcate professional boundaries in response to teamwork. Methods: Semi-structured interviews, observations and documents were used. The interviewed individuals were seven dentists employed at two clinics, the managers of each clinic and the general manager. The dentists were interviewed to investigate how they defend or blur professional boundaries. They were also observed at work. The clinic managers and the general manager were interviewed to identify their expectations of dentists concerning work division. The documents comprised organisational plans and annual reports. Results: Dentists demarcated professional boundaries by utilising various power resources: treatment responsibility, specialist knowledge, discretion, and avoidance of work considered to be low status work. The dentists also contributed to blurred boundaries between themselves and the other dental professionals by discussing patient treatment, giving and receiving advice, and assisting the others in skill development. Conclusion: Although dentists' boundary work could obstruct implementation of policy objectives, dentists' behaviour contributed to effective collaboration within the teams. 
Boundary work of dentists

Key words: boundary work, dentists, multi-professional team, qualitative research, work division

\section{Introduction and theoretical framework}

Collaboration between various professional groups in health and medical care is an issue of current interest in many countries. This is also true for the Swedish dental care system. In recent years, government reports have discussed ideas about multi-professional teams of dentists, dental hygienists and dental nurses who work together in caring for patients (1-6). “Dental Care to 2010” (4), a Swedish government official report on future dental care, underlines that the choice of an appropriate caregiver in dental care must be individually assessed and need not always include a dentist. The inquiry argues that this must be a consideration if future public demands for dental care are to be met. The number of practicing dentists is decreasing while dental care needs are not. Although younger people do take better care of their teeth, older patients are expected to retain their teeth longer, which translates into growing demands on the dental care system. Delivery of dental care to all who are in need of it will require that dentists focus on the treatments that they alone are skilled enough to perform, while dental hygienists and dental nurses are delegated all other clinical duties within their respective fields. Yet another argument for this task division is that because financial resources are limited, the dental staff must be utilised in the best possible manner. Discussions on how best to utilise members of dental staff are also frequent in other western countries (7-14). 
This paper deals with how dentists in the Swedish Public Dental Service (PDS) respond to demands for teamwork. Teamwork and the idea of the provision of care at the lowest effective levels have become a valuable way of organising care in the Nordic taxfinanced public service models (14). In Sweden, dental care is free of charge for children up to the age of 19 while dental care of adults is partially funded by taxation.

Previous research indicates that dentists can be positive to teamwork (13) and appreciative of the contribution dental hygienists make to improving practice profitability, efficiency, and accessibility of dental services to patients (11). Dentists often delegate prevention work because they perceive other staff to be under less time pressure and delegation enables dentists to focus on more complex treatments (13). But sources also describe dentists as obstacles to more efficient dental care since they can be unwilling to assign work tasks to dental hygienists and dental nurses. When this occurs, it may be because dentists are uninformed of other professionals’ skills $(4,9,13)$, uninformed of others’ permitted duties (10), and offered too little training in being a team leader during their dental training (4). According to dental hygienists, barriers to effective teamwork in dental care are routines, rigid work traditions, and dentists’ willingness to perform simple tasks to avoid more taxing workloads (14).

Some studies report that conflicts may occur between dentists and dental hygienists concerning who should examine the patients. The basis of this conflict is the underlying notion that the group of professionals that examines the patients will also decide which patients to treat and who should treat them. This means that if dental hygienists perform the examination, dentists are relinquishing some of the power that comes with examining a patient $(7,15)$. There may, on the other hand, be no conflicts between dentists and 
dental hygienists concerning periodontal treatment and preventive dental care services. Such tasks are not considered status work tasks within dental care so dentists do not claim an exclusive right to perform them (15).

Despite previous investigations, more research is needed on ways to optimise dental care teamwork and how dentists decide which patients and which tasks to delegate to other dental professionals (13). This paper furthers such research by examining the boundary work of dentists in the Swedish PDS. The theoretical point of departure is that professional boundaries have come under pressures as a consequence of demands for teamwork $(16,17)$. Teamwork may cause professional groups to try to create or maintain boundaries around their profession. This process is also called boundary work (16). The theory is that professions compete with one another for control over a field of work and for an exclusive scope of practice (18). Competition for work tasks may also include avoidance of certain work tasks, those considered to be “dirty work” (19).

Professional groups lay claim to work tasks in three arenas: within the legal system, via public opinion, and at the workplace (18). The legal system guarantees a professional group reserved rights to perform specified work tasks through licensing or authorisation and legislation that regulates the work tasks of individual professional groups $(20,21)$. Authorisation and legislation, however, do not always give a professional group reserved rights to perform certain work tasks. Other professional groups may perform similar or equivalent work tasks (21).

Workplaces can be viewed as micro-political arenas in which professional groups create and maintain boundaries that regulate who should do what, when, how and why $(22,23)$. Professionals may utilise various power resources to stand out in a competition 
Boundary work of dentists

and maintain their interests and control over their work (24). Support may come from (i) laws and regulations that are formal and strong power resources and (ii) educational resources, such as degrees, authorisation, and specialist skills. Other power resources may be introduced: (iii) informal, such as gender, age, or time of employment, (iv) organisational, such as treatment responsibility, managerial responsibility, or financial responsibility, and (v) professional, such as a high level of discretion inherent to the profession. The discretion of professionals means that they have the power and control to decide what tasks to perform and how to perform them (25). Another power resource of professionals is (vi) defining the status of the work task. Characterisation of a work task as being simple, complicated, boring, or important affects its status (22).

Negotiated order theory is a related approach that is useful in studies of interpersonal relations in health care $(23,26,27)$ because it shows how negotiations contribute to the construction or maintenance of professional boundaries and that the social order at workplaces is not fixed but dynamic (26). In the negotiation process, professionals make decisions about how work should be organised and who will do what and when (23).

Laws, regulations and the licensing of dentists and dental hygienists constitute the framework for the distribution of work in the Swedish dental care. There is room, however, for negotiations on the work tasks that can be performed by the three professional groups, that is dentists, dental hygienists and dental nurses. During their 5year higher education, Swedish dentists are trained to examine, diagnose and perform all kinds of treatments. Some treatments only dentists are licensed to perform, such as excavation of caries in teeth, surgical procedures, pulp and root canal treatment, and prosthetic procedures. The Swedish dental hygienist training programme is a 2-year 
Boundary work of dentists

higher education programme. Swedish dental hygienists are licensed to work independently and to examine and diagnose caries and periodontal disease. Their main focus is prevention of caries and periodontal disease. They also treat periodontal disease by scaling and are permitted to fill but not to drill tooth cavities, to perform X-rays and to administer local anaesthetics. The dental nurse training programme was formerly part of the upper secondary school system but today belongs to the vocational higher education system and is a 1.5-2-year training programme. Swedish dental nurses are trained to assist dentists in treatment of patients. They are qualified to take X-rays and certain impressions and carry out preventive dental care after assignment of a dentist (28). Swedish legislation allows dentists to assign treatment work to a nurse only in accordance with the nurse’s competence.

In most cases, a dentist examines a patient the first time he or she visits a clinic. The dentist then decides what treatment may be needed, who should perform it, and whether the patient needs to see a dentist or a dental hygienist at the next visit. It is possible that a patient first visits a dental hygienist who performs the examination and then requests a dentist to complete the examination in areas in which the dental hygienist is unqualified (4). Swedish government reports emphasise that dental hygienists should be offered more prominent roles in examination and preventive dental care services for children $(1,3)$ and adults (5). The duties of dental nurses should not only be to assist dentists but also to perform patient-oriented work tasks (28).

Professional relations in multiprofessional health care teams have traditionally been studied, and recent investigations have focused on the microprocesses by which professional boundaries are constructed, maintained, and eliminated (17, 23, 26, 27, 29- 
Boundary work of dentists

31). Salhani \& Coulter (27) report that an understanding of the micro-political struggles is vital to grasping the formation of interprofessional relations at workplaces, through which various forms of collaboration can be identified. Earlier studies on teamwork in dental care have not been anchored in mundane arenas in which dentists may try to demarcate or break down professional boundaries. Thus, the aim of this paper is to describe and analyse dentists' negotiations of the boundaries between them and other dental professionals in the context of PDS clinics.

\section{Methods}

The empirical material is based on a case study conducted in one Swedish PDS organisation and concerns the capacity of managers to influence how dentists view themselves as dentists and their dental work (32). That study touched upon dentists' role in the division of work tasks. This article develops the role of dentists by viewing clinics as micro-political arenas.

In the study, interviews, observations and documents were used. The individuals selected for the interviews were the general manager in the PDS in question, the clinical managers at two clinics, and seven dentists employed at the clinics. Four of the dentists worked at one clinic and three at the other. Selection of the dentists was based on length of work experience: 2 years was the criterion so that the dentists would have had a chance to form some opinion on work and working relations. Sampling continued until there was sufficient empirical data to make and justify interesting conclusions (33).

Qualitative semi-structured interviews were conducted from spring 2003 to spring 2004. A qualitative, rather than a quantitative, study is best suited for examining people’s 
Boundary work of dentists

opinions (34), and according to negotiated order theory, focus should be on professionals’ talk about themselves and their work (26). Nonetheless, it is important to point out that interviews do not allow a full understanding of the thoughts and feelings of the interviewees. An interview is a complex social interaction in which the interviewer and the interviewee constantly exert influence (35). All interviews were conducted in the workplaces of the interviewees.

Dentists were interviewed for 1.5 to 2 hours on two occasions. The questions concerned what work tasks they assigned to dental hygienists and dental nurses and how they viewed their relationship with other dental staff members. The general manager was interviewed on one occasion for about 2 hours. The clinical managers were interviewed on two occasions for a total of 3 hours. The general manager and clinical managers answered questions about the requirements they placed on dentists concerning work division. Some of the questions asked at the second interview were follow-ups to the responses given at the first interview and some questions were new, depending on what the dentists and clinical managers had said on the first occasion.

Dentists were also observed in their work. The purpose of the observation was to deepen the understanding of what the dentists had related at their interviews. The observations were thus helpful during the interview analysis.

Before the start of the study, all participants were informed in writing and verbally about the aim of the study, that their participation was voluntary, and that their identity would not be revealed. The research ethics committee at the medical faculty in Lund approved the study. 
Boundary work of dentists

The documents included in the study were organisational plans and performance reports written by the general manager and clinical managers. Documents offer information on organisational contexts and may be used to determine the credibility of interviewee statements (36). These documents confirmed statements made by the general manager and clinical managers in their interviews, which makes their answers credible.

\section{Data analysis}

The interviews were tape-recorded and later transcribed verbatim. In the analysis, the dentists' statements were categorised into themes. These themes were derived from the interviews and from the theory of workplaces as micro-political arenas where professional boundaries are negotiated. Thus, the analysis was a process of abduction that constantly moved between the empirical data and the theoretical departure of the study (37). The themes concerned how the dentists used power resources when they demarcated professional boundaries and how the dentists contributed to blurred boundaries. The themes were then organised into two overarching dimensions before similarities and variations between the dentists' accounts within these dimensions were analysed.

\section{Results}

The work context

The dental staff worked in teams, as recommended in Swedish government reports. The managers expected the dentists to assign work tasks to the dental hygienists and dental 
Boundary work of dentists

nurses. The objective was for dental hygienists to examine the healthy patients every second year.

\section{Dentists as gatekeepers}

Most of the dentists said that they let dental hygienists examine healthy patients every second year. Dentist M, however, the one with the least work experience, said that he would rather examine the patients himself; dentist M emphasised his treatment responsibility: 'I feel that I am responsible for their (the patients') dental health.' Dentist $\mathrm{M}$ also said that he had only been working for a few years and that, for this reason, he wanted to see the patients the following year to follow up treatment and learn from any mistakes. 'This early on it is important to learn on your own before allowing someone else to do things for you.'

Dentists emphasised their treatment responsibility when discussing the role of dental nurses during patient examinations and whether dental nurses should work directly with patients. Some of the dentists regularly allowed dental nurses to X-ray patients, administer anaesthetics, take impressions, and make temporary crowns while others did not; two of these, dentist A and dentist $\mathrm{K}$, said this was because they wanted to retain control of the patient work. Dentist A, who had previously worked in two treatment rooms, said:

I felt that I never had the time to sit down and properly read through a patient's case history, that I was constantly tackled new things and that the dental nurse was the one who knew what to do. But could I really trust that the nurse knew for certain? 
Boundary work of dentists

When asked if she had been afraid of losing control, she answered 'yes'. Dentist K also claimed that a downside of this work method is that 'I do not fully know what is written in the journal.'

The importance of being in control of the content of patient's records was also brought up by dentist M. He said that he makes all entries in the patient records rather than allowing a dental nurse to do so, only to have to read through them afterward and sign them. In contrast, some of the other dentists would usually let a dental nurse make entries. Once again dentist $\mathrm{M}$ claimed treatment responsibility: 'I feel it is important. I have the responsibility.' Similarly, dentist E said: 'If I have discussed something important with a patient or performed root fillings, I always write this myself. It is important to be able to trust the figures the next time you look.'

When talking about letting dental nurses perform treatment tasks, dentist K drew a boundary between herself and dental nurses, emphasising that dentists are in possession of specialist knowledge. She said: 'You study to become a dentist for a reason, you acquire certain knowledge about patients and I feel that you should take good care of that knowledge and not delegate everything.' Some of the dentists demarcated the professional boundary between themselves and dental nurses, pointing out that, as dentists, they make the treatment decisions; an example of discretion. Dentist E said: 'I am the dentist and control the room'. Dentist K, who worked at the same clinic, said: 'I decide what is to be done.' Similarly, dentist J did not think that she must perform all treatments: 'a dental nurse can do them', but 'dental nurses do not make decisions on their own.' 
Boundary work of dentists

Dentists' response to which tasks they preferred concerned dental surgeries, prosthetic procedures, and treatment of children. Periodontal treatment and preventive dental care were areas that they claimed could be delegated to another profession. Preventive dental care for children and young people was delegated to dental nurses and all dentists said that they allowed dental hygienists to treat adult patients who needed plaque and calculus removed or who needed preventive dental care because of severe caries. The dentists said they assigned such duties to dental hygienists because they were good or even better than the dentists themselves at these tasks. Dentist E offered a different explanation, that he wished to avoid boring work tasks: 'Something I really do not like doing is nagging people about how to use a toothbrush properly.'

\section{Blurring professional boundaries}

Besides demarcating their professional boundaries, dentists also contributed to blurred boundaries between them and the other dental staff. Some dentists said that they were willing to help the dental hygienists with a patient during examination or treatment. Dentists sometimes also offered dental hygienists a chance to develop their skills. Dentist A said that she allowed the dental hygienist she works with to make fillings after she herself has drilled out a cavity in a tooth, because the dental hygienist wished to learn the skill. Doing fillings are part of a dental hygienist's job description, but in reality, the dentists usually do the fillings. Dentist $\mathrm{K}$ also said that she allowed dental hygienists to 'do exams and simpler fillings.'

Two of the dentists, dentist $\mathrm{D}$ and dentist H, said that they showed dental nurses Xrays if they were uncertain when they should diagnose caries. Dentist D said: 'Of course 
Boundary work of dentists

they ask me, but I ask them as well.' Similarly, dentist H said: 'I often show the X-rays to the dental nurses or hygienists when I am a little uncertain. What do you think, I ask, and they have a look.' Dentist H said that he taught dental nurses to 'diagnose caries' so that they would be more involved in the patient work. The reason for this, he said, was that 'it must be much more fun for them too' to be part of the patient work compared to simply sitting and assisting him.

A further blurring of the boundaries between dentists and the dental nurses occurred when the nurses gave the dentists advice. Dentist $\mathrm{J}$ and dentist $\mathrm{M}$ stated that they were happy for recommendations. Dentist J said: 'I am bold enough to admit when something is difficult because the dental nurses can help me. Sometimes they are more experienced than I am.'

\section{Discussion}

In Sweden, government reports strongly recommend that dental staff work in teams and that dentists offer the other professionals opportunities to work according to their skill levels. This work method is considered a necessary tool for meeting public demands of dental care and for increasing the cost-effectiveness of the dental sector.

Political intentions, however, are not easily implemented in the day-to-day work of organisations. Previous studies have reported factors may influence dentists’ decisions on which patients and which tasks they may assign to other dental professionals. In view of the theoretical point of departure of professional boundary work, this study cast new light on dental care teamwork and dentists' role in the division of work. 
The present study was able to show how dentists utilised power resources to safeguard or avoid certain work tasks. The professional boundaries between dentists, dental hygienists and dental nurses are to some extent stipulated in legislation; however, there is room for negotiation on the work tasks that can be performed by dentists, dental hygienists as well as dental nurses. All dentists in this study assigned preventive care of children and adolescents to dental nurses and periodontal treatment and preventive care of adults to dental hygienists. At least one of the dentists said this was because these work tasks were boring. In other words, the dentist utilised a power resource for what he considered was low status work. A Canadian study (15) found similar views on such work tasks. As a consequence of avoiding preventive and periodontal treatment, the dentists were able to focus on treatments that only they had been trained to perform.

The interviewed dental teams could have worked more efficiently. Dentists were expected to let dental hygienists examine healthy patients every second year, but not all dentists supported this idea. The dentist who safeguarded the right to perform examinations did so by claiming treatment responsibility. Previous research has shown that dentists are unwilling to assign examinations of patients to dental hygienists since this means losing influence over decisions concerning treatment choice and who should perform treatment (15). In other words, another reason for safeguarding the right to examine patients emerged in this study. Other dentists said that they did not want dental nurses involved in the examination of patients. These dentists based their view on arguments concerning treatment responsibility, discretion and specialist knowledge.

In this study, work boundaries between the dentists and the other professionals on the dental team were not always clear-cut. By contributing to this blurring of work 
boundaries, the dentists effectively improved collaboration, creating a situation where team members could help and learn from each other.

The response of the dentists in this study to their managers' requests to assign work tasks to dental hygienists and dental nurses varied, which may be explained by differences in personal values, interests, and work experiences. The differences are not surprising. A profession should not be regarded as a homogenous occupational group in which all members respond similarly to managerial demands. They are not victims but actors evaluating and placing themselves in relation to managerial ideas of work (38).

The literature recommends numerous strategies for improving collaboration between professional groups, such as training programmes and communication training. The disadvantage of these recommendations is that they tend to disregard the competition that can occur between professional groups and which makes it difficult to collaborate (27). Is there a solution to competition in dental care? One might be to allow future dentists, dental hygienists, and dental nurses to work together earlier, during their training, and through this learn how to work together and learn more about each other's professional skills (4). Another solution might be rewards for meeting financial targets. It has been shown that bonuses based on clinic performance can improve assignment of work tasks to dental hygienists and dental nurses in the PDS (39). A third solution rests on the organisation of dental care in Sweden, which allows patients to choose their dentists, thus engendering competition. Patients could themselves request to be treated not only by a dentist but also by a dental hygienist. Collaboration between the professional groups would perhaps then improve as work task division can be determined by patients in a market exposed to competition (40). Offering dental care that includes meetings with 
Boundary work of dentists

dentists as well as dental hygienists could thus be one way to strengthen a clinics' ability to compete. Findings of general public trust in the care provided by dental hygienists support this option (41). More studies, however, are needed.

The results of this study are based on interviews and observations of dentists. The two methods of data collection ensure comprehensiveness of the data compared to if only one of the methods had been used (42). The author has worked as a dentist. Having a background similar to that of the participants can be advantageous as it facilitates understanding of participants' meanings, ideas, and feelings. On the other hand, it can make it difficult for the researcher to keep a necessary, critical distance to the empirical data and the analysis (35). In this study, the theories used in the analysis helped create this distance. Other researchers might have interpreted the empirical data differently because the outcome of a qualitative study depends on the researcher and the theoretical framework $(35,37,42)$.

This paper is based on a case study conducted some years ago in the Swedish PDS. Because the Swedish National Board of Health and Welfare emphasised the importance of teamwork for efficient use of resources in 2009 (6), the results are still relevant in the Swedish context. The results are also relevant for dental services in other western countries because previous studies have shown that dentists are expected to assign work tasks to other dental professionals. Thus, the present study can contribute to deeper understanding of the role of dentists for the division of work that can be helpful for managers and staff members within dental organisations, not only in the Swedish PDS. 
Boundary work of dentists

\section{Acknowledgements}

I thank Peter Dellgran, Andreas Liljegren and Lennart Svensson for their comments on an earlier version of the paper, presented at the 2010 Conference on Professional Studies in Gothenburg, Madeleine Rohlin, as well as the anonymous reviewers. This article is based on material from my doctoral thesis. The Faculty of Odontology at Malmö University funded the study. 
Boundary work of dentists

\section{References}

1. Swedish Competition Authority. Dental care and competition. (report in Swedish). Stockholm: Swedish Competition Authority, 2004.

2. Swedish National Board of Health and Welfare. The role of dental nurse in the future dental care: work tasks, level of education and demand. (report in Swedish). Stockholm: Swedish National Board of Health and Welfare, 2004.

3. Swedish National Board of Health and Welfare. Expanded competence for dental hygienists - condition for experimental work. (report in Swedish). Stockholm: Swedish National Board of Health and Welfare, 2007.

4. Swedish Government Official Report 2002:53. Dental care to 2010. (report in Swedish with English summary). Stockholm: Ministry of Health and Social Affairs, 2002.

5. Swedish Government Official Report 2006:27. Support for health promoting dental care. (report in Swedish). Stockholm: Ministry of Health and Social Affairs, 2006.

6. Swedish National Board of Health and Welfare. The 2009 Swedish Health care Report. (report in Swedish). Stockholm: Swedish National Board of Health and Welfare, 2009.

7. Abelsen B, Olsen JA. Task division between dentists and dental hygienists in Norway. Community Dent Oral Epidemiol 2008; 36: 558-66.

8. Baltutis L, Morgan M. The changing role of dental auxiliaries: a literature review. Aust Dent J 1998; 43: 354-8. 
Boundary work of dentists

9. Czikar JI, Bradley S, Williams SA, Godson JH, Rowbotham JS. Dental therapy in the United Kingdom: part 4. Teamwork - is it working for dental therapists? Br Dent J 2009; 207: 529-36.

10. Gallagher JL, Wright DA. General dental practitioners' knowledge of and attitudes towards the employment of dental therapists in general practice. Br Dent J 2002;193: $37-41$.

11. Hopcraft M, McNally C, Ng C, Pek L, Pham TA, Phoon WL et al. Attitudes of the Victorian oral health workforce to the employment and scope of practice of dental hygienists. Aust Dent J 2008; 53: 67-73.

12. Kwan SYL, Prendergast MJ. The use of clinical dental auxiliaries as examiners in caries prevalence surveys in the United Kingdom: a feasibility study. Community Dent Oral Epidemiol 1998; 26: 194-200.

13. Nilchian F, Rodd HD, Robinson PG. Influences on dentists’ decisions to refer paediatric patients to dental hygienists and therapists for fissure sealants: a qualitative approach. Br Dent J 2009; 207: E13.

14. Virtanen JI, Tseveenjav B, Wang N J, Widström E. Nordic dental hygienists’ willingness to perform new treatment measures: barriers and facilitators they encounter. Scand J Caring Sci 2011; 25: 311-16.

15. Adams TL. Inter-professional conflict and professionalization: dentistry and dental hygiene in Ontario. Soc Sci Med 2004; 58: 2243-2252.

16. Fournier V. Boundary work and the (un)making of the professions. I Malin N, editor: Professionalism, boundaries and the workplace. London: Routledge, 2000. 
Boundary work of dentists

17. Sanders T, Harrison S. Professional legitimacy claims in the multidisciplinary workplace: the case of heart failure care. Sociol Health Illn 2008; 30: 298-308.

18. Abbott A. The system of professions. An essay of the division of expert labor. Chicago: The University of Chicago Press, 1988.

19. Hughes EC, Coser LA. On work, race, and the sociological imagination. Chicago: The University of Chicago Press, 1994.

20. Freidson E. Professional reborn. Theory, prophecy and policy. Cambridge: Polity Press; 1994.

21. Macdonald KM. The sociology of the professions. London: Sage, 1995.

22. Liljegren A. Professional boundary work: social workers in Sweden. Department of social work, University of Gothenburg. 2008. Dissertation. (in Swedish with English abstract).

23. Svensson R. The interplay between doctors and nurses - a negotiated order perspective. Sociol Health Illn 1996; 18: 379-98.

24. Freidson E. Professional powers: a study of the institutionalization of formal knowledge. Chicago: The University of Chicago Press, 1986.

25. Lipsky M. Streel-level bureaucracy: dilemmas of the individual in public services. New York: Russell Sage Foundation, 1980.

26. Allen, D. The nursing-medical boundary: a negotiated order? Sociol Health Illn 1997; 19: 498-520.

27. Salhani D, Coulter I. The politics of interprofessional working and the struggle for professional autonomy in nursing. Soc Sci Medicine 2009; 68: 1221-28. 
Boundary work of dentists

28. Swedish National Board of Health and Welfare. Who is permitted to do what in health- and medical care and dental care? (report in Swedish). Stockholm: Swedish National Board of Health and Welfare; 2004.

29. Carmel S. Boundaries obscured and boundaries reinforced: incorporation as a strategy of occupational enhancement for intensive care. Sociol Health Illn 2006; 28: 154-77.

30. Martin GP, Currie G, Finn R. Reconfiguring or reproducing intra-professional boundaries? Specialist expertise, generalist knowledge and the 'modernization' of the medical workforce. Soc Sci Medicine 2009; 68: 1191-98.

31. Mizrachi N, Shuval JT, Gross S. Boundary at work: alternative medicine in biomedical settings. Sociol Health Illn 2005; 27: 20-43.

32. Franzén C. To be a dentist in the public dental service. Faculty of Odontology, Malmö University. 2009. Dissertation. (in Swedish with English summary).

33. Wood LK, Kroger RO. Doing discourse analysis. Methods for studying action in talk and text. London: Sage, 2000.

34. Miles MB, Huberman, AM. Qualitative data analysis: an expanded sourcebook. London: Sage, 1994.

35. Alvesson M, Deetz S. Doing critical research. London: Sage, 2000.

36. Yin RK. Case study research. Design and methods. London: Sage, 2003.

37. Alvesson M, Sköldberg K. Reflexive methodology: new vistas for qualitative research. London: Sage, 2000.

38. Halford S, Leonard P. New identities? Professionalism, managerialism and the construction of self. In Exworthy M, Halford S, editors: Professionals and the new managerialism in the public sector. Buckingham: Open University Press, 2002. 
Boundary work of dentists

39. Modell S. Management control in services. A contingency study of responsibility accounting in highly interactive services. University of Karlstad. Dissertation.

40. Freidson E. Professionalism: the third logic. Oxford: Polity Press, 2001.

41. Edginton E, Pimlott J. Public attitudes of independent dental hygiene practice. J dent Hyg 2000; 74: 261-69.

42. Mays N, Pope, C. Assessing quality in qualitative research. BMJ 2000; 320: 50-2. 